\title{
Tips for GP trainees working in accident and emergency
}

Spending time in the emergency department is something that every doctor should experience, but most particularly the GP trainee. A\&E represents the front line of secondary care and experience accrued here is very relevant to the GP. The rotation allows you to put your medical knowledge on fast-forward, as you will be seeing a lot of patients in a short period of time. There is no substitute for experience. You will see a lot. You will do a lot. You will experience medicine, surgery, psychiatry, paediatrics, gynaecology, orthopaedics and often social work all in the same shift.

You will be expected to work hard. The hours are long and the rota punishing. The pace at the weekends can be unrelenting. There may be managerial pressures about target times. To begin with you may be reeling from the environment but it's not all bad news. You will learn more in this rotation about pathology, injury, and 'real world' presentations than you ever have before. Crucially you will learn how to manage and treat these presentations effectively; skills that are very transferable to general practice. Many GP trainees love the A\&E setting as it has all the variety of general practice but with ready access to investigations. Teamwork is important, communication is key and work can be rewarding, stimulating, challenging and fun!

The following list of tips is designed to help the trainee feel more comfortable and confident in the emergency department and help them get the most from their rotation.

1. Don't be late.

2. Take your allotted breaks, you'll need them. Remember to keep hydrated.

3. The nurses and healthcare assistants are your friends, be nice and courteous from the start of your job and they'll save your bacon when you need them later on. Be rude and impolite and your life can be made very difficult!

4. Be patient with your patients and most particularly beware the patient you don't like. Make sure that they are investigated properly.
5. Remember - the general public don't have the same knowledge as you so try not to be patronising or condescending when communicating.

6. Always explain what you are doing to patients and relatives; it may seem obvious to you but they may be scared and/or unfamiliar with hospital procedure.

7. The Oxford Handbook of Emergency Medicine, and Raby's Accident \& Emergency Radiology: A Survival Guide are both worth owning.

8. Learn how to put in nasal packs.

9. Learn to suture before you arrive.

10. Know your antimicrobial policies (or how to access them) as it's best for the patients and will prevent a summons from your medical director/microbiology consultant.

11. Beware NSAIDs in the over 60s.

12. Always document discussions with relatives and collateral history as the specialty you refer to may not have the luxury of the information when they get to the patient.

13. Always document medication lists accurately not just 'see list with patient' as pieces of paper go missing and the referring team will be unaware of the details. Don't forget that beta blockers mask a tachycardia; check the drug list for clues to potential causative agents for admission.

14. Don't forget to comment on effect of treatment and clearly state the time after it was administered (that is, wheeze/recession in children postbronchodilators, chest pain after GTN).

15. Learn the resuscitation guidelines for common presentations including asthma, anaphylaxis, arrthymias, and so on. Got an iPhone? Iresus is a free app.

16. Don't avoid the resus room, skills learned there will be vital in whichever career path you choose.

17. If you are wondering whether or not to do an $A B G$; do the $A B G$. A venous gas can also be very useful, but tell the machine it is venous so it doesn't re-calibrate inappropriately.
18. Learn your local acute coronary syndrome (ACS) management pathway inside out - you'll be seeing a lot of it.

19. Always examine the abdomen in patients with back pain or chest pain. If you don't look for a abdominal aortic aneurysm (AAA) you are unlikely to find one. Anticoagulating a AAA misdiagnosed as ACS would be a bad mistake for the sake of a thorough physical examination.

20. Beware diagnosing first episode renal colic in older people.

21. Be suspicious of constipation that requires morphine for analgesia.

22. When examining an undressed patient keep an eye out for malignant melanomas, regardless of their presentation. Malignant melanoma kills young people and is on the increase.

23. Missing testicular torsion can be catastrophic - be very sure of your diagnosis before discharging epididymitis without a urology opinion.

24. Epistaxis treatment is ALWAYS airway breathing circulation (an older patient could have significant blood loss prior to attending A\&E).

26. Know the Ottowa Ankle and Knee Rules inside out - this will save time and worry later.

27. Always examine the joint above and below the injured joint. Document these findings.

28. Always check hand dominance and profession and accurately document sensation in hand injuries.

29. Don't miss the second fracture after noticing the obvious first one that jumped out at you from the screen first.

30. Fractured neck of femur in the under 65's is an orthopaedic emergency. Fractured neck of femur over 65 is bread and butter for the orthopods but fracture in a young patient of working age has a different set of guidelines and targets.

31. In trauma, bear in mind the concept of distracting injury.

32. Familiarise yourself with the NICE guidelines for CT head. Check how these fit with local guidelines. 


\section{Professor lan Richardson}

33. Avoid arguing with patients who are drunk and remember the drunk patient may have an intracranial bleed.

34. All women of childbearing age are pregnant until a urinary beta-hcg test says they are not.

35. You will see a lot of children. Most love stickers. If possible spend a minute talking to the parents to put them and their child at ease. Use this time to observe the child before examining. Obviously this isn't practical in an emergency.

36. Don't discharge a febrile child on antibiotics without finding a source of infection.

37. Don't ever forget the glucose.

38. A\&E is a great environment to develop your ophthalmology skills so make the most of this opportunity. Learn to use the slit lamp (preferably before you use it on a patient) but don't become too dependant on it as few GP practices have one. Always document visual acuity and eye movements in any eye/facial injury.

39. Always check patient details before requesting investigations/tests on the computer or sending bloods.

40. Don't forget to ask for paracetamol and salicylate levels in all cases of overdose and serious deliberate self-harm no matter what report to have taken (or not taken) - these are the things that CAN be treated.

41. Always check renal function before IVU or other radiological contrast.

42. Try to avoid handing patients over if possible. If it isn't possible, hand over a clear management plan that covers the likely outcomes. Your colleague doesn't want to have to re-clerk the patient.

43. Try to stay professional when referring, even if the person you're referring to isn't.

44. Encourage patients who don't have a GP to register with one, this is better for them and can save you work in the future.

\section{Matthew Burkes, Ben Atkinson and Kate H Bunyan}

DOI: 10.3399/bjgp11X561429

\section{Professor of General Practice, born 3 April 1922, died 16 December 2010}

Among the festive debris on our kitchen table at the end of last year, were two letters lying, by chance, alongside one another. One was from my aged mum, an avid reader of the Herald obituary column, enclosing an obituary of Professor lan Richardson, professor of general practice in Aberdeen, and one was from the widow of Gibbie Abercrombie, the Auckland GP with whom I had done my GP student attachment.

As a student in Aberdeen in the early 70s, I had approached Professor Richardson to explore possibilities for doing an attachment in New Zealand. He was encouraging and kind and, rather than, as I had imagined, querying why I wanted to leave the Aberdeenshire fold, he contacted an old friend and colleague then living and working in Auckland and, several months later, I was welcomed into Gibbie's home and practice. Two months after that, I decided that I wanted to be a GP.

Gibbie had graduated from Edinburgh and had managed to combine medical studies and working as a doctor with playing rugby for Scotland. He and his wife emigrated and he set up practice on Auckland's North Shore. They had three sporting sons and several sporting grandchildren and a happy and fulfilled life until, around the age of 60 , he developed motor neurone disease. My memory is of a very active, kind man who loved life, his work and thrived on helping people. ( $\mathrm{He}$ might have been surprised that one of his grandsons forsook rugby for basketball. But he would have forgiven him when he gained a place on the NZ national team, the Tall Blacks.)

As a student from a non-medical, nonuniversity educated family, I had often felt intimidated and vulnerable in a medical teaching environment where nearly everyone else seemed to speak the language and identify with the system. Both Gibbie and Professor Richardson encouraged me to feel that wider life experiences were valuable and that they contributed to how you practised and what kind of doctor you were. As Professor John
Howie said in Professor Richardson's obituary:

'He was devoted to the well-being of students. He nurtured young talent and promoted inter-disciplinary thinking and working ...' ${ }^{1}$

In 1966, he had been appointed as a reader in the embryonic General Practice Teaching Unit and became professor in 1970, focusing on developing a pioneering health centre strategy for Aberdeen. He was responsible for producing the north-east Scotland workload study which provided data for research over the subsequent decade, promoted the idea of the 10-minute consultation ahead of its time and created a 12-place vocational training scheme. $\mathrm{He}$ was influenced by the work of Michael Balint and was involved with the RCGP, going on to chair the Board of Examiners.

My personal experience of him was of someone who listened, was non-judgmental and helpful to an undistinguished student with no overt academic aspirations:

\section{'His legacy is in the careers of countless people who were inspired by his thoughtfulness, his wise counsel ...'}

What a privilege to have met and had my early life and career influenced by him. Thank you, Professor Richardson.

\section{Lesley Morrison}

\section{Postscript}

For anyone seeking to encourage potential medical students, especially those from backgrounds where family advice is not easily available, the website www.wanttobeadoctor.co.uk is invaluable. Produced by Leeds WAMS, Widening Access to Medical School scheme, it is a very useful resource for students applying to any medical school.

\section{REFERENCE}

1. Obituary: Professor Ian Richardson, professor of general practice. News. Scotland.com 2010; Dec 22 http://news.scotsman.com/obituaries/ObituaryProfessor-Ian-Richardson-professor.6667957.jp (accessed 8 Jan 2011).

DOI: 10.3399/bjgp11X561438 